\title{
Laser Scanning and Photogrammetric Evaluation of Uzuncaburç Monumental Entrance ${ }^{\#}$
}

\author{
Murat Yakar ${ }^{1}$, Ali Ulvi ${ }^{2}{ }^{2}$, Ahmet Suat Toprak ${ }^{3}$, Ömer Mutluoğlu ${ }^{4}$
}

Accepted $15^{\text {th }}$ August 2014

Abstract: This studied in Ayaş, Erdemli the town of Mersin. In this study it is aimed 3D modeling of Historical Uzuncaburç monumental entrance by the using of both methods; Terrestrial Laser scanning, Terrestrial photogrammetric methods. At first, it is coordinated with the targets which are studied on the historical gate. These coordinates are approved as the the reference coordinates. The coordinates of these targets are obtained with help of both terrestrial laser scanning and terrestrial photogrammetric method. These coordinates are compared with the accurate coordinates and made a sensibility research. In this project Optech laser scanner is used to obtain 3D point datas. These point clouds are combined by Polyworks software and the terrestrial photogrammetric drawings are done by Photomodeler software.

\section{Keywords: Laser Scanning, Terrestrial Photogrammetry, 3D model, Point Cloud}

\section{Introduction}

In recent years ,the use usage of laser scanning systems on 3D modeling works is increasing. In this system the modeling of the objects are done with the help of point cluster. All points which are in the point clouds, have 3D coordinates. In a few minutes thousands of 3D points can be obtained about the mentioned object. Terrestrial object has been used for this used for this purpose for years. Terrestrial laser scanning is a quite new method for 3D modeling. Although terrestrial laser scanning has some disadvantages, it has important advantages. These advantage scan be listed below; directly obtaining the 3D points, quite effective on defining the formless structures, and obtaining the results in a short time. Limited distance, high imaging expenditure and not obtaining the attribution of the object, are the primary disadvantages [1].

\section{Terrestrial Laser Scanning Technology}

Terrestrial laser scanning technology is a new developing technology which is used for 3D modeling of the objects. Today, the most popular measuring system for laser scanners is "Time of flight". This technique enables to measure the identified distance for several 100 meters. Besides, phase measuring principle is another partner technique. At this technique distance is limited in 100 meters. Accuracy of measured distance is just a few $\mathrm{mm}$. Some terrestrial laser scanners can measure up to several $\mathrm{m}$. Those are used in more industrialized applications. Optic triangulation is the kind of distance measuring principle which is used in this kind of terrestrial laser scanners. The accuracy of these measures are at micron levels. Terrestrial laser scanners can be group according to their technical features below [2-5].

${ }^{2}$ Selcuk University, The Vocational School Of Hadim, Konya/Turkey

* Corresponding Author:Email: aliulvi@selcuk.edu.tr

\# This paper has been presented at the International Conference on Advanced Technology\&Sciences (ICAT'14) held in Antalya (Turkey), August 12-15, 2014.

This journal is ( ) Advanced Technology \& Science 2013
Table 1. The classification of terrestrial laser scanner

\begin{tabular}{|c|c|c|}
\hline $\begin{array}{c}\text { MEASURING } \\
\text { SYSTEM }\end{array}$ & DISTANCE(m) & ACCURACY (mm) \\
\hline Time Of Flight & $<100$ & $<10$ \\
\cline { 2 - 3 } & $<1000$ & $<20$ \\
\hline Phase Measuring & $<100$ & $<10$ \\
\hline Optic Triangulation & $<5$ & $<1$ \\
\hline
\end{tabular}

2.2.The differences that differs the terrestrial laser scanners from traditional measuring techniques

The most effective way of terrestrial laser scanners is capturing the 3D geometry of the objects directly, fast and detailed.

Other advantages in order: [3]

1- The impressive decrease of expenditures

2- Complenting the Project much faster. The Project can

be completed in a few days.

3- It can measure at complex, in accessible, dangerous

objects and areas where the traditional techniques failed.

4- $\quad$ As the scanning process does not depend on the

lighting. It is possible to scan even at night.

5- Completeness and comprehensiveness at scanning: It can capture everything at one time. Thus, if any information is needed, it is not necessary to go back to the scaning area. this also rises the trust of the user fort the result.

6- $\quad$ From now on, multiple purposed data usage.

\section{Study Area}

This work is done in Uzuncaburç, Silifke the town of Mersin. The gate is, through the North-South direction on the second pillar road and on the North of the Zeus temple, which has three entrance; one is in the middle and big and the others are on the 
both sides of the middle one. The coordinates are $36^{\circ} 34^{\prime}$ 53,8 "north, $33^{\circ} 55^{\prime} 25,60^{\prime \prime}$ east (Figure 1). The 3 arched structure has 31 meters length and 12 meter high. The gate is dated in $2^{\text {nd }}$ century AD. This gate is one of the most important structures of the historical city because there is a tablet on it which is written the name of the city, "Diokaesareia". By this tablet, we are able to learn that this gare was restored the roman imsikketor Arcadius (AD 395- 408) and Honorius (AD 395- 423).

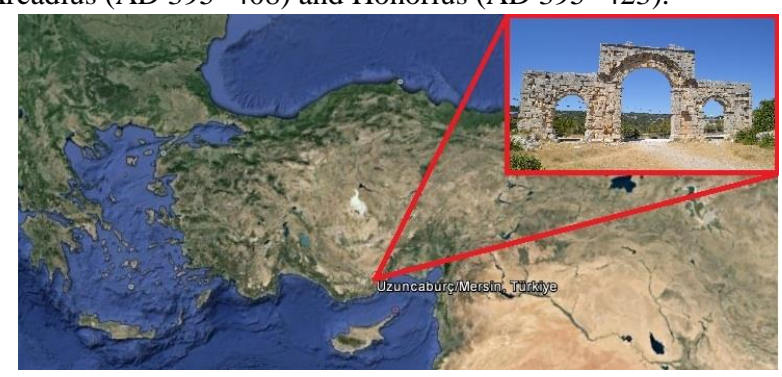

Figure1. The position of the Uzuncaburç gate on the earth

\section{4- Material- Method}

Two different technique is used to complete the work at filed. First one is terrestirial laser scanning, the other one is photogrammetric. During the pre-study process of modeling, the Uzuncaburç gate, laser scanning tool and electronic total station (Figure 2 and 3), the target papers which are stuck on the walls, are provided(Figure 4)

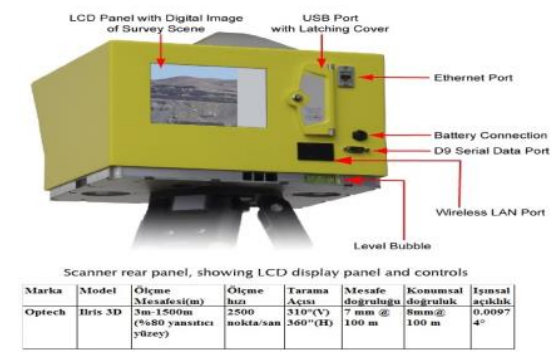

Figure 2. Optech Ilris 3D laser scanner
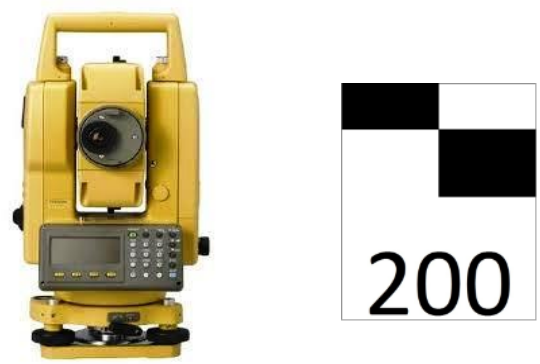

Figure3.Total Station GPT 3007 Figure 4.A4 photocopy paper shaped target sheet

After the preparations had finished at the field, the measurement of the control points at the study started. Angles and distances are measured by Total Station GPT 3007 laser and vertical, horizontal and oblique distances are measured by laser Total Station (Figure 5). And also coordinates are obtained with these devices.

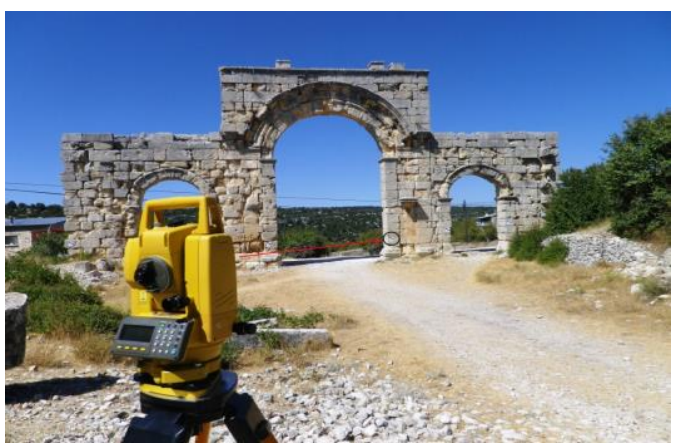

Figure 5. The coordination of the control points with total station

\subsection{The application of terrestrial laser scanning at Uzuncaburç Gate}

The study which we applied has two process. One is at the area, the other one is at the office. The area work includes scanning the area with laser scanning devices. Office work includes the transferring of data to computers or to suitable applying devices which is obtained during the area work. The area work takes 1 day and Office work takes 3 days long. The scanning of the castel gate with terrestrial laser scanning is applied on six different scanning station. Each scanning is applied at the partner points with in at least 4 link points. The scanning process is applied Optech Ilris 3D laser scanning device with in $1 \mathrm{~cm}$ points density. The scanning process is controlled by its own controller programme of the scanner "controller" (Figure 6 and 7).

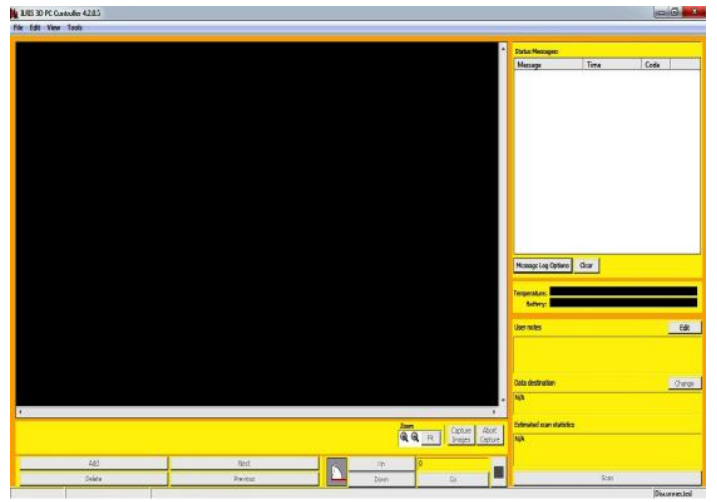

Figure 6. The interface of the controller programme

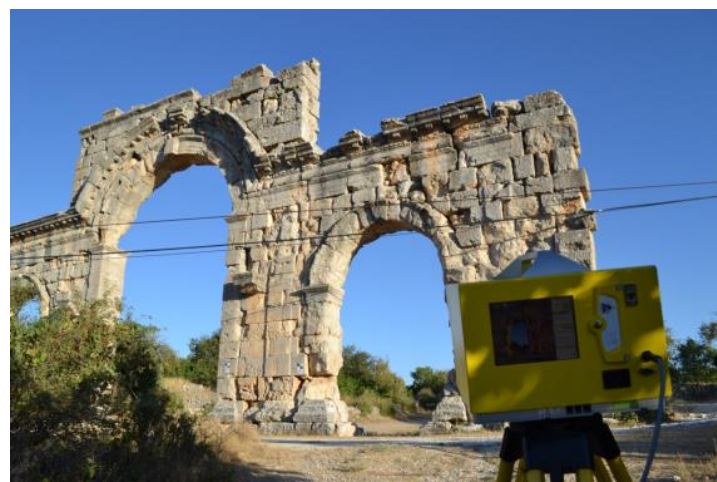

Figure 7. The terrestrial laser scanning process at the field

At first, the datas which are collected during the field work, are transformed into PIF, XYZ, RAV,IXF extensions etc. by Parser programme (Figure 8). 


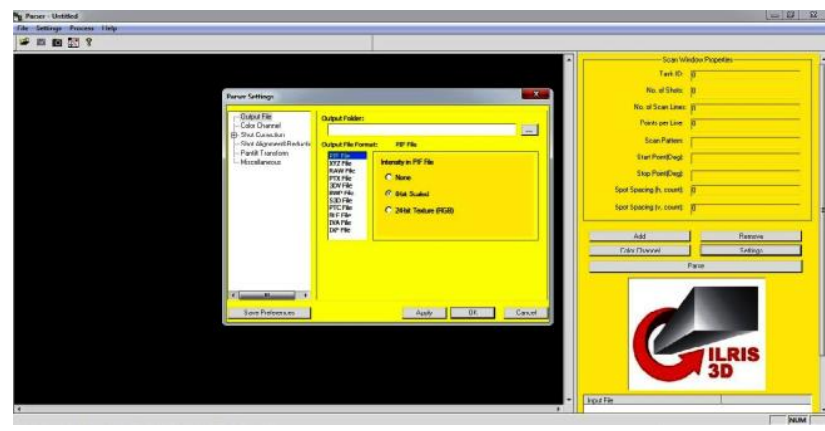

Figure 8. The interface of parser programme

The files, whose extension are transformed, then opened with polyworks programme and combined with it. The combination process is applied while two different point clouds partner point is is defined. At the end of this process, the point clouds of the castle gate is obtained (Figure 9 and 10).

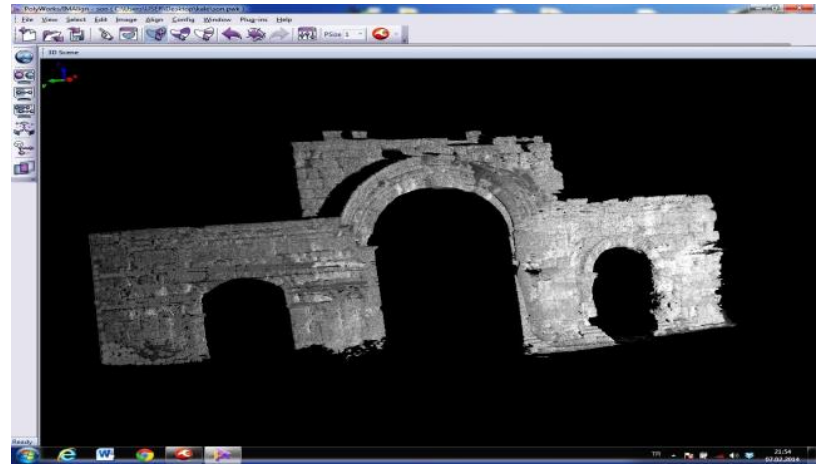

Figure 9. The point clouds of the front side of the castle gate

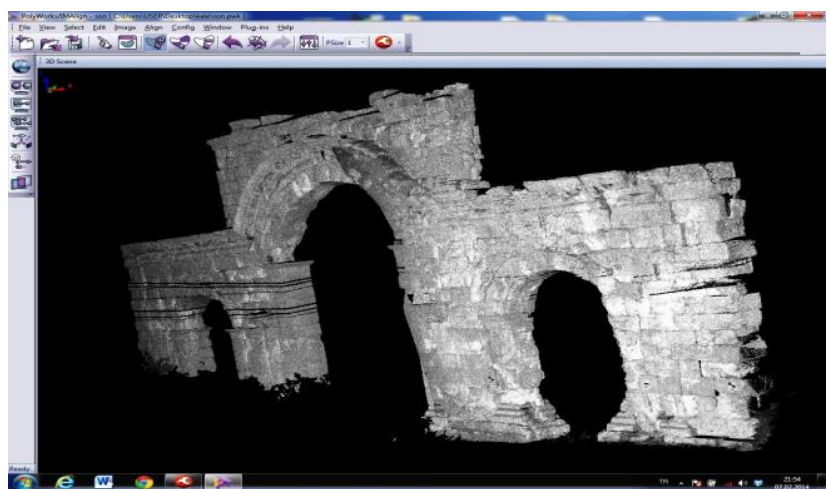

Figure 10. The point clouds of the front side of the castle gate

\subsection{The application of the terrestrial photogrammetric} method at Uzuncaburç gate

First of all photography work is completed in terrestrial photogrammetric study. Photographing was made by Nikon camera D3100 (Figure 11 and 12).

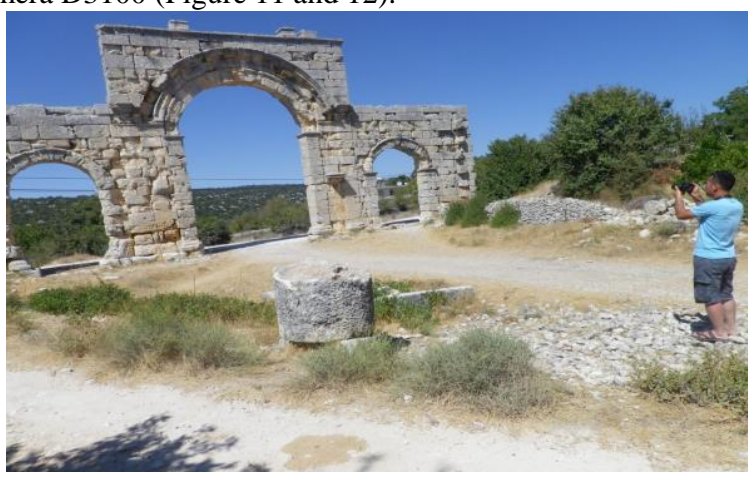

Figure 11.The photo taking of castle gate

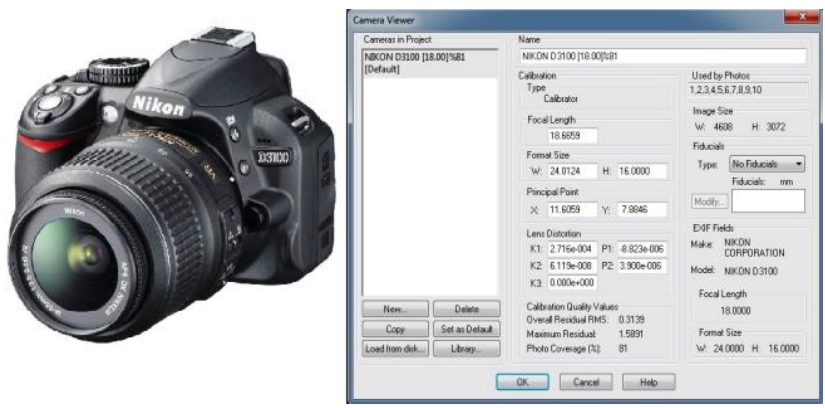

Figure 12. The calibration rates of Nikon D3100 camera

After completing the photo taking process, the taken photos are balanced, drawn (Figure 13), and illustrated (Figure 14) Photomodeler Scanner programme.

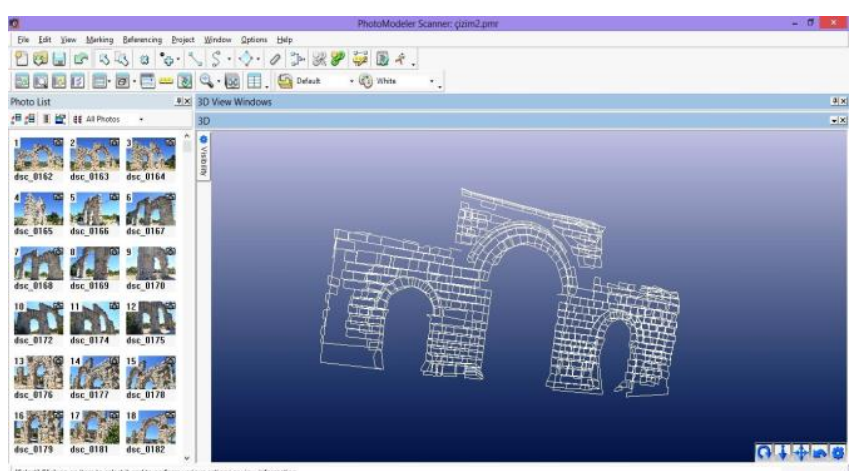

Figure 13. Drawing the castle gate on Photomodeler programme

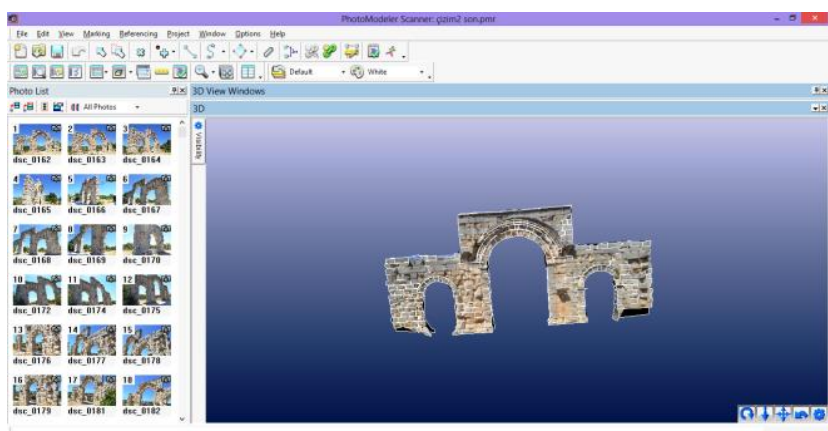

Figure 14. The illustration of image match process

\section{Findings}

The 20 paper points (Figure 15) which are stuck on castle walls, are coordinated by total station. The coordinates are confirmed as the exact coordinates.

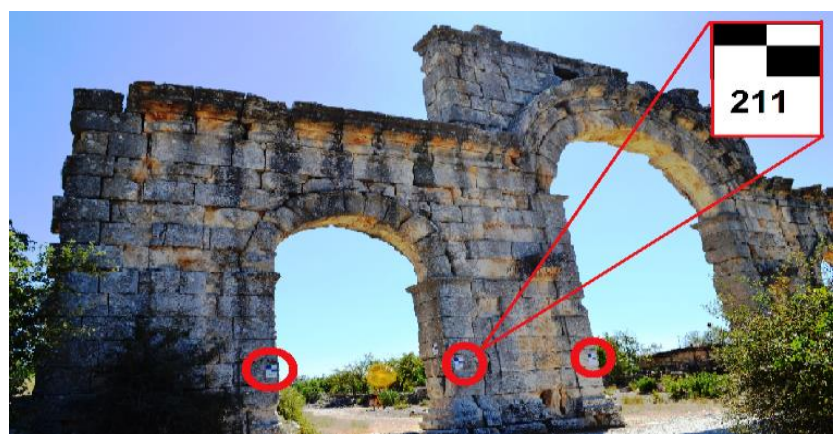

Figure 15. Sticking the paper target on the object

The coordinates of the 20 points are calculated by both using the results of laser scanning and the terrestrial photogrammetric 
techniques. These coordinates are given in the Table-1.

Table-1.The exact coordinates, the coordinates which are calculated by using the laser scanning and terrestrial photogrammetric techniques

\begin{tabular}{|c|c|c|c|c|c|c|c|c|c|}
\hline \multicolumn{4}{|c|}{ EXACT COORDINATES } & \multicolumn{3}{|c|}{$\begin{array}{l}\text { LASER SCANNING } \\
\text { COORDINATES } \\
\end{array}$} & \multicolumn{3}{|c|}{$\begin{array}{l}\text { TERRESTRIAL } \\
\text { PHOTOGRAMMETRIC } \\
\text { COORDINATES } \\
\end{array}$} \\
\hline N.N & $\mathbf{Y}$ & $\mathbf{x}$ & $\mathrm{z}$ & $\mathbf{Y}$ & $\mathbf{x}$ & $\mathrm{z}$ & $\mathbf{Y}$ & $\mathbf{x}$ & $\mathrm{z}$ \\
\hline 211 & 730.384 & 1081.278 & 1010.255 & 730.376 & 1081.273 & 1010.251 & 730.38 & 1081.276 & 1010.252 \\
\hline 212 & 733.439 & & 09.717 & 733.436 & 1081.959 & & & 1081.959 & \\
\hline 213 & 737.692 & 1082.928 & 1009.04 & 737.698 & 1082.922 & 1009.045 & 737.696 & 1082.926 & 1009.043 \\
\hline 214 & 740.911 & 1083.687 & 1009.745 & 740.916 & 1083.691 & 1009.748 & 740.914 & 1083.686 & 1009.745 \\
\hline 215 & 748.05 & 1085.398 & 1009.799 & 748.057 & 1085.403 & 1009.796 & 748.053 & 1085.396 & 1009.794 \\
\hline 216 & 751.52 & 86.207 & 1010.29 & 751.522 & 1086.203 & 1010.296 & 751.521 & 1086.205 & 1010.296 \\
\hline 217 & 755.438 & 1087.143 & 1010.71 & 755.435 & 1087.148 & 1010.711 & 755.435 & 1087.147 & 1010.713 \\
\hline 218 & 757.759 & 87.619 & 11.314 & 757.756 & 1087.615 & 011.317 & 557.757 & 1087.615 & 1011.312 \\
\hline 219 & 755.1 & 1087.655 & 1010.736 & 755.097 & 1087.655 & 1010.738 & 755.102 & 1087.657 & 1010.733 \\
\hline 220 & 3.885 & 2.701 & 09.603 & 733.885 & 1082.704 & 009.607 & 33.881 & 1082.703 & 09.609 \\
\hline 221 & 738.039 & 1084.254 & 1010.151 & 738.035 & 1084.258 & 1010.155 & 738.035 & 1084.256 & 1010.158 \\
\hline 223 & 730.175 & 1082.406 & 1010.274 & 730.179 & 1082.409 & 1010.272 & 730.178 & 1082.402 & 1010.274 \\
\hline 224 & 732.685 & 1082.988 & 010.227 & 732.688 & 1082.983 & 1010.223 & 732.682 & 1082.985 & 1010.222 \\
\hline 225 & 737.108 & 1083.912 & 1009.011 & 737.102 & 1083.91 & 1009.014 & 737.105 & 1083.915 & 1009.012 \\
\hline 226 & 751.646 & 1087.014 & 1010.725 & 751.641 & 1087.018 & 1010.728 & 751.641 & 1087.019 & $\begin{array}{l}1010.729 \\
\end{array}$ \\
\hline 227 & 747.707 & 1085.939 & 1009.813 & $\begin{array}{r}747.709 \\
\end{array}$ & 1085.936 & 1009.819 & 747.709 & 1085.932 & 1009.819 \\
\hline 228 & 741.19 & 1084.873 & 1009.831 & 741.194 & 1084.878 & 1009.834 & 741.194 & 1084.875 & 1009.839 \\
\hline 229 & 740.753 & 1084.921 & 1010.286 & 740.758 & 1084.924 & 1010.282 & 740.758 & 1084.924 & 1010.282 \\
\hline 230 & 747.754 & 1086.568 & 0.211 & 747.75 & 1086.563 & 1010.208 & 747.759 & 1086.565 & 1010.21 \\
\hline 23 & 5.12 & 1088.3 & 1010.233 & 5.126 & 1088.301 & 010.231 & 755.122 & 1088.304 & 1010.239 \\
\hline
\end{tabular}

With the help of using the differences of characteristic point coordinates at castle gate (Table-2), for each coordinate component sensibility standards are identified.

Table-2.The differences between the exact coordinates and, the coordinates obtained from laser scanning and photogrammetric

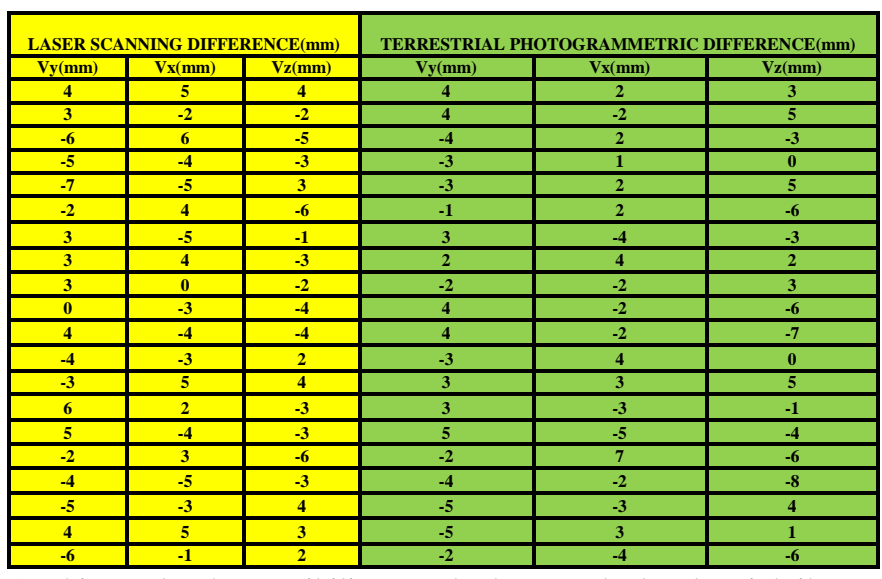

At this grade, the sensibility standards are calculated weightily. $\mathrm{S}_{\mathrm{o}}=20 \mathrm{~m}$ unit distance is chosen as the average distance between total station and the object points, weight $\mathrm{Pi}=20 /$ si equality is determined for each point (Table-3).

Table-3. weights and distances from the total Station points

\begin{tabular}{|c|c|c|}
\hline & & Weight $(\mathrm{So}=20 \mathrm{~m})$ \\
\cline { 3 - 3 } N.N & Distance(Si=m) & Pi=20/Si \\
\hline 211 & 14.12 & 1.416 \\
\hline 212 & 15.79 & 1.267 \\
\hline 213 & 18.76 & 1.066 \\
\hline 214 & 21.35 & 0.937 \\
\hline 215 & 27.67 & $\mathbf{0 . 7 2 3}$ \\
\hline 216 & 30.88 & $\mathbf{0 . 6 4 8}$ \\
\hline 217 & 34.61 & 0.578 \\
\hline 218 & 36.81 & 0.543 \\
\hline 219 & 25.02 & 0.799 \\
\hline 220 & 9.81 & 2.039 \\
\hline 221 & 10.77 & 1.857 \\
\hline 223 & 9.49 & 2.107 \\
\hline
\end{tabular}

This journal is (C) Advanced Technology \& Science 2013

\begin{tabular}{|c|c|c|}
224 & 9.18 & 2.179 \\
\hline 225 & 10.4 & 1.923 \\
\hline 226 & 21.76 & 0.919 \\
\hline 227 & 18.26 & 1.095 \\
\hline 228 & 12.84 & 1.558 \\
\hline 229 & 12.45 & 1.606 \\
\hline 230 & 18.11 & 1.104 \\
\hline 232 & 24.94 & 0.802 \\
\hline
\end{tabular}

With the help of weightedly found results point cloud changes is tried to be identified.3D location accuracy is calculated as in formula(1). [4].

(1)

$$
\text { Weighted } \quad S x_{0}=\sqrt{\frac{P V x V x]}{n-1}} S y_{0}=\sqrt{\frac{P V V x V x]}{n-1}} S z_{0}=\sqrt{\frac{P V x V x]}{n-1}}
$$

$$
\begin{aligned}
& \text { 3D location accuracy } S_{3 B}=\sqrt{S x_{0}^{2}+S y_{0}^{2}+S z_{0}^{2}} \\
& S x_{i}=\frac{S x_{0}}{\sqrt{P i}} \quad S y_{i}=\frac{S y_{0}}{\sqrt{P i}} \quad S z_{i}=\frac{S z_{0}}{\sqrt{P i}}
\end{aligned}
$$

$$
\text { 3D location accuracy } \quad S_{3 B_{i}}=\sqrt{S x_{i}^{2}+S y_{i}^{2}+S z_{i}^{2}}
$$

As a result of weighted evaluation location accuries which are calculated for each point,are calculated according to formula (2) and the results are given at Table-4.

Table-4.Weight (Different sensibility) found values standart

\begin{tabular}{|c|c|c|c|c|c|c|c|c|c|}
\hline \multirow{2}{*}{\multicolumn{3}{|c|}{$\begin{array}{l}\text { Weighted Values }(\mathrm{mm}) \\
\text { (Laser } \\
\text { Scanning) }\end{array}$}} & \multirow{2}{*}{\multicolumn{7}{|c|}{$\begin{array}{c}\text { Weighted Values (mm) } \\
\text { (Terrestrial } \\
\text { Photogrammetry) }\end{array}$}} \\
\hline & & & & & & & & & \\
\hline N.N & Sy(i) & Sx(i) & Sz(i) & 3B-Si & N.N & Sy(i) & Sx(i) & Szzi) & 3B-Si \\
\hline 211 & 4.054 & 3.762 & 3.474 & 6.127 & 211 & 3.489 & 3.041 & 4.48 & 6.442 \\
\hline 212 & 4.288 & 3.979 & 3.674 & 6.447 & 212 & 3.69 & 3.216 & 4.738 & 6.812 \\
\hline 213 & 4.673 & 4.337 & 4.004 & 6.976 & 213 & 4.022 & 3.505 & 5.164 & 7.425 \\
\hline 214 & 4.986 & 4.627 & 4.272 & 7.403 & 214 & 4.29 & 3.739 & 5.509 & 7.921 \\
\hline 215 & 5.676 & 5.267 & 4.863 & 8.348 & 215 & 4.884 & 4.257 & 6.272 & 9.018 \\
\hline 216 & 5.996 & 5.564 & 5.138 & 8.786 & 216 & 5.16 & 4.497 & 6.626 & 9.526 \\
\hline 217 & 6.348 & 5.891 & 5.439 & 9.267 & 217 & 5.462 & 4.761 & 7.015 & 10.085 \\
\hline 218 & 6.546 & 6.075 & 5.609 & 9.538 & 218 & 5.633 & 4.91 & 7.234 & 10.401 \\
\hline 219 & 5.397 & 5.008 & 4.624 & 7.966 & 219 & 4.644 & 4.048 & 5.964 & 8.575 \\
\hline 220 & 3.38 & 3.136 & 2.896 & 5.201 & 220 & 2.908 & 2.535 & 3.735 & 5.369 \\
\hline 221 & 3.541 & 3.286 & 3.034 & 5.423 & 221 & 3.047 & 2.656 & 3.913 & 5.626 \\
\hline 223 & 3.324 & 3.085 & 2.848 & 5.124 & 223 & 2.86 & 2.493 & 3.673 & 5.281 \\
\hline 224 & 3.269 & 3.034 & 2.801 & 5.049 & 224 & 2.813 & 2.452 & 3.613 & 5.194 \\
\hline 225 & 3.48 & 3.229 & 2.981 & 5.338 & 225 & 2.994 & 2.61 & 3.845 & 5.528 \\
\hline 226 & 5.033 & 4.671 & 4.313 & 7.468 & 226 & 4.331 & 3.775 & 5.562 & 7.997 \\
\hline 227 & 4.611 & 4.279 & 3.951 & 6.89 & 227 & 3.968 & 3.458 & 5.095 & 7.325 \\
\hline 228 & 3.866 & 3.588 & 3.313 & 5.869 & 228 & 3.327 & 2.9 & 4.273 & 6.143 \\
\hline 229 & 3.807 & 3.533 & 3.262 & 5.788 & 229 & 3.276 & 2.856 & 4.207 & 6.049 \\
\hline 230 & 4.592 & 4.261 & 3.934 & 6.864 & 230 & 3.951 & 3.444 & 5.074 & 7.295 \\
\hline 232 & 5.388 & 5.000 & 4.617 & 7.954 & 232 & 4.637 & 4.042 & 5.955 & 8.561 \\
\hline
\end{tabular}
deviation

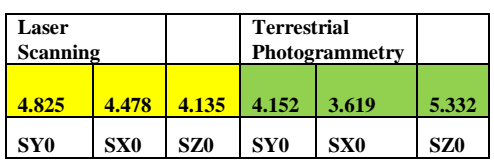

Table-5. Weightedly found 3D location accuracies (For each points)

Both standart deviation values of weighted standart and 3D location accuracies for each points are obtained from formula(3) (Table-5).

$\mathrm{t}$-test is applied considering the coordinate differences and their standard deviation is known during the examining of whether the coordinate differences are meaning or not. Calculated test greatness is given in Table-6.These values are compared degrees of freedom ( $\mathrm{f}=\mathrm{n}-1)$ and error probability $\alpha=0.05$ with in the limit value at $t$-chart.t-test limit value is (Considerin degrees of freedom $\mathrm{f}=20-1$ and error probability $\alpha=0.05) 2.09$.

Table- 6 is examinated,it is seen that all the values are below the limiting values. 


\begin{tabular}{|c|c|c|c|c|c|c|c|}
\hline \multicolumn{5}{|c|}{ Laser Scanning } & \multicolumn{3}{|c|}{$\begin{array}{c}\text { Terrestrial } \\
\text { Photogrammetry } \\
\end{array}$} \\
\hline N.N & $T y=V i / S y i$ & $\mathrm{Tx}=\mathrm{Vi} / \mathrm{Sxi}$ & $\mathrm{Tz}=\mathrm{Vi} / \mathrm{Szi}$ & N.N & $\mathrm{Ty}=\mathrm{Vi} / \mathrm{Syi}$ & $T x=V i / S x i$ & Tz=Vi/Szi \\
\hline 211 & 0.987 & 1.329 & 1.151 & 211 & 1.146 & 0.658 & 0.670 \\
\hline 212 & 0.700 & -0.503 & -0.544 & 212 & 1.084 & -0.622 & 1.055 \\
\hline 213 & -1.284 & 1.383 & -1.249 & 213 & -0.995 & 0.571 & -0.581 \\
\hline 214 & -1.003 & -0.865 & -0.702 & 214 & -0.699 & 0.267 & 0.000 \\
\hline 215 & -1.233 & -0.949 & 0.617 & 215 & -0.614 & 0.470 & 0.797 \\
\hline 216 & -0.334 & 0.719 & -1.168 & 216 & -0.194 & 0.445 & -0.906 \\
\hline 217 & 0.473 & -0.849 & -0.184 & 217 & 0.549 & -0.840 & -0.428 \\
\hline 218 & 0.458 & 0.658 & -0.535 & 218 & 0.355 & 0.815 & 0.276 \\
\hline 219 & 0.556 & 0.000 & -0.432 & 219 & -0.431 & -0.494 & 0.503 \\
\hline 220 & 0.000 & -0.957 & -1.381 & 220 & 1.375 & -0.789 & -1.607 \\
\hline 221 & 1.130 & -1.217 & -1.318 & 221 & 1.313 & -0.753 & -1.789 \\
\hline 223 & -1.203 & -0.973 & 0.702 & 223 & -1.049 & 1.604 & 0.000 \\
\hline 224 & -0.918 & 1.648 & 1.428 & 224 & 1.066 & 1.223 & 1.384 \\
\hline 225 & 1.724 & 0.619 & -1.006 & 225 & 1.002 & -1.149 & -0.260 \\
\hline 226 & 0.993 & -0.856 & -0.696 & 226 & 1.154 & -1.324 & -0.719 \\
\hline 227 & -0.434 & 0.701 & -1.519 & 227 & -0.504 & 2.024 & -1.178 \\
\hline 228 & -1.035 & -1.394 & -0.906 & 228 & -1.202 & -0.690 & -1.872 \\
\hline 229 & -1.313 & -0.849 & 1.226 & 229 & -1.526 & -1.051 & 0.951 \\
\hline 230 & 0.871 & 1.173 & 0.763 & 230 & -1.265 & 0.871 & 0.197 \\
\hline 232 & -1.113 & -0.200 & 0.433 & 232 & -0.431 & -0.990 & -1.008 \\
\hline
\end{tabular}

\section{Results}

Terrestrial laser scanning technology which boots the creation of 3D modeling studies, has been started to use widely day by day. It has been presenting an important role as it is faster and more practical on the studies of especially preserving historical and cultural heritages, relieve and documenting studies. The sensibilities ,obtained at both methods, reached us a conclusion with these techniques that they could be base for further restoration works. In conclusion of these documenting techniques. it is understood that by sending the documents to their appropriate usage opportunities, there can be a data interaction between different disciplines, and a decrease on expenditures. The usage of this system is getting wider ,especially in engineering, and it ensures advantages like time ,cost and labor decreasing. Considering that coordinate differences and their standard deviating are calculated-test is applied in order to understand whether the coordinates(obtained both total station and laser scanner) are meaningless or not. When t-test results are examined ,it is seen that all results are below the limited values.

\section{References}

[1] Demir, N., Bayram, B., Alkış, Z., Helvacı, C., Çetin, I., Vögtl, T., Ringle, K., Steinle, E., 2004, “Laser Scanning for Terrestrial Photogrammetry, Alternative System or Combined with Traditional System", ISPRS xx. Symposium, Com. V., WG V/2, 12-23 July 2004, İstanbul.

[2] Fröhlich, C., Mettenlaiter, M., 2004, "Terrestrial Laser Scanning- New Perspectives 3D Surveying", ISPRS xx. Symposium, Com. V., WG V/4, 12-23 July 2004, İstanbul.

[3] Yuriy Reshetyuk "Investigation and calibration of pulsed time-of-flight terrestrial laser scanners" Department of Transport and Economics Division of Geodesy 10044 Stockholm

[4] Aydın Ö. (1984), Ölçme Bilgisi 1, İstanbul Erkaya H. ve Hosbaş G. (2006), Konum Ölçmeleri Ders Notları, İstanbul

[5] Schulz, T., Ingesand, H., 2004, "Terrestrial Laser ScanningInvestigations and Applications for High Precision Scanning”, FIG Working Week, 22-27 May, Athens. 